\title{
INTIMIDAD Y RELATO DE INFANCIA ${ }^{1}$
}

\section{INTIMACY AND CHILDHOOD AUTOBIOGRAPHIES}

\author{
Celia FERNÁNDEZ PRIETO \\ Universidad de Córdoba \\ fe1feprm@uco.es
}

\begin{abstract}
Resumen: El relato autobiográfico de infancia se entiende en este artículo como una de las representaciones literarias más renovadoras de la intimidad en la medida en que implica la reconstrucción imaginaria de un yo infantil que ya no existe, pero habita como un fantasma la memoria del adulto. Esta presencia fantasmática toma formas diversas en los relatos de infancia de Annie Ernaux y de Luis Landero, cuya escritura indaga en la persistencia actual de los sentimientos de vergüenza (en la primera) y de culpa (en el segundo), y en la dificultad de recordarlos y contarlos.
\end{abstract}

Palabras clave: Relato de infancia. Intimidad. Luis Landero. Annie Ernaux.

Abstract: The autobiography of childhood is taken in this article as one of the most innovative literary representations of intimacy in that it implies the imaginary reconstruction of a childhood self that no longer exists but inhabits as a ghost the memory of the adult. This ghostly presence adopts different forms in the childhood autobiographies of Annie Ernaux and Luis Landero, whose writing explore the ongoing persistence of feelings of shame (in the former) and guilt (in the latter), and the difficulty in

${ }^{1}$ Este artículo se inscribe en el marco del proyecto de investigación franco-español "Figures et frontières de l'intime à l'époque contemporaine / Figuras y fronteras de la intimidad en la época contemporánea" (OPE-2017-0042), de la Universidad de Pau et des Pays de l'Adour EFM (FR 4153), ALTER (EA7504), ITEM (EA 3002) en colaboración con el grupo de investigación «Lenguajes» (HUM 224) de la Universidad de Córdoba (España) y el laboratorio "Arts Plastiques" (EA 7472) de la Universidad de Rennes 2 (Francia). 
remembering and expressing those feelings.

Key Words: Childhood autobiographies. Intimacy. Luis Landero. Annie Ernaux.

\section{INTRODUCCIÓN}

El relato de infancia es un subgénero de la autobiografía centrado en la evocación de la infancia del autobiógrafo y que finaliza generalmente en la adolescencia, aunque a veces se extiende hasta el inicio de la juventud. Su publicación de manera aislada y autónoma, no integrado en la narración extensa de una trayectoria vital, se inicia a mediados del siglo XIX aunque con diferente arraigo según los países ${ }^{2}$-, se consolida a lo largo del siglo XX y se incrementa en las primeras décadas del nuestro. Las razones de este auge son muy diversas: recordemos que la concepción temporal y causalista de la infancia dominante hasta el siglo XVIII, se fue transformando y cargando, sobre todo desde el Romanticismo, de adherencias simbólicas y metafóricas que otorgaron a la infancia un valor específico, una dimensión de alteridad. Es decir, el niño ya no se define negativamente en relación al adulto por lo que le falta, o por lo que ignora, sino que se constituye en un otro yo con perfiles (físicos, psicológicos, morales o sociales) propios y cualitativamente diferenciados del modo de experiencia del sujeto adulto. La niñez deviene así, culturalmente, no tanto una fase anterior en el desarrollo del individuo humano, cuanto un estado interior ${ }^{3}$ solo accesible a través de la introspección: "la infancia no sólo remite a un pasado, sino que se deja entender también como una presencia interior y esencializante ligada a la identidad más íntima (homogénea y atemporal) del adulto" (Cabo, 2001: 55). Por tanto, la representación de la infancia ya no se subordina al programa narrativo de una historia de

\footnotetext{
${ }^{2}$ Richard Coe (1984) considera Henry Brulard (1835) de Sthendal como la primera Chilhood. Para Philippe Lejeune (2003: 84), el relato de infancia aislado aparece en la primera mitad del XIX en la lírica y en la literatura para los jóvenes. Aislado y ficticio, en torno a 1860; y aislado y autobiográfico a finales de siglo. Ricardo Fernández Romero (2007) sitúa en Recuerdos de niñez y mocedad (1908) de Miguel de Unamuno los orígenes del relato de infancia en la literatura española. 3 "La infancia no es una edad - leemos en Días del desván (1997) de Luis Mateo Díez- sino un estado de inocencia y sabiduría ciega, que alimenta el sufrimiento más benigno de la memoria" (1997: 127).
} 
vida, sino que adquiere una dimensión autónoma, idealizada en la versión romántica como el mito del origen, el periodo del descubrimiento y el asombro ante el mundo, el paraíso perdido al que se anhela regresar. Una especie de "utopía retrospectiva" (Cabo, 2001: 52).

Por otra parte, desde principios del siglo XX, la teoría psicoanalítica de Sigmund Freud contribuyó a otorgar a la infancia un relieve excepcional, por encima de cualquier otra de las edades del hombre, al descubrir los efectos determinantes de las experiencias vividas de niño en la posterior conformación moral y emocional de la identidad adulta, en sus conflictos y desequilibrios. Recordemos que para Freud buena parte del material onírico procede de recuerdos de situaciones acontecidas en los primeros años de la vida, irrecuperables por la memoria, pero no olvidadas.

El imaginario de la infancia va rebajando en el siglo XX ese halo romántico en favor de una visión menos complaciente y más lúcida: el adulto sabe que nunca hubo un paraíso, o que el paraíso ocultaba miseria y dolor, o que la inocencia puede ser cruel y despiadada. La infancia aparece como un proceso de crecimiento en el que el niño afronta sentimientos ambivalentes, y experimenta angustia, miedo y desolación, tal como lo evoca el narrador de Infancia (1997) de Coetzee:

La infancia, dice la Enciclopedia de los niños, es un tiempo de dicha inocente, que debe pasarse en los prados, entre ranúnculos dorados $y$ conejitos, o bien junto a una chimenea, absorto en la lectura de un cuento. Esta visión de la infancia le es completamente ajena. Nada de lo que experimenta en Worcester, ya sea en casa o en el colegio, lo lleva a pensar que la infancia sea otra cosa que un tiempo en el que se aprietan los dientes y se aguanta (Coetzee, 2000: 19).

Si entendemos la intimidad como la conciencia del propio cuerpo y de sus cambios, y el ámbito de los procesos mentales conscientes ${ }^{4}$

\footnotetext{
${ }^{4}$ Tengamos en cuenta que los neurocientíficos han subrayado que gran parte de la actividad diaria cerebral es inconsciente. Así, David Eagleman explica que "Lo primero que aprendemos al estudiar nuestros propios circuitos es una lección muy simple: casi todo lo que hacemos, pensamos o sentimos no está bajo nuestro control consciente. Los inmensos laberintos neuronales aplican sus propios programas. El tú consciente - ese yo que poco a poco vuelve a la vida cuando despierta por la mañana - es el fragmento más pequeño de lo que ocurre en tu cerebro [...]. El actúa por su cuenta" (2013: 12). Ya Freud había planteado que la mayoría de nuestros procesos psicológicos eran inconscientes, pero que mediante los procedimientos del psicoanálisis se podían hacer, al menos en
} 
(recordar, pensar, sentir), el relato autobiográfico de infancia y juventud puede considerarse como una de sus representaciones literarias más intensas y renovadoras. Tener intimidad supone que el ser humano es capaz de replegarse o de volverse sobre sí mismo, de ensimismarse (en expresión de Ortega y Gasset), de apartarse de las exigencias de la vida social, pública y privada, para atender los movimientos "del alma" decir, para elaborar su relación - afectiva, ética, estética, política...consigo mismo y con los otros, una relación en continuo movimiento de ajuste y desajuste porque la identidad, el saber quién se es, es un proceso que nunca se puede considerar concluido y firme:

No tengo intimidad porque yo sepa quién soy, sino porque soy aquel para quien nunca se agota el sentido de la pregunta ¿Quién soy?, la pregunta menos fundamental del menos fundamental de los saberes [...], el saber de sí mismo, el saber acerca de la falta de saber, acerca de la falta de fundamento de la propia existencia, el saber (sabor) de la intimidad (Pardo, 1996: 51).

Pero la intimidad no se reduce a ese repliegue hacia dentro, sino que es también un sentimiento que se crea en la relación con los demás y se traduce en la vivencia consciente e inconsciente de que el yo y el otro comparten el mismo espacio emocional (Bleichmar, 1999). De ahí las dos formas indisociables y complementarias que adopta la intimidad: por una parte, el deseo de conocer y proteger lo íntimo en su singularidad y precariedad, asociado al secreto y al silencio, y, por otra, el deseo de expresarlo y comunicarlo para establecer un vínculo con los otros que le reconozca su valor y su verdad (lo que Serge Tisseron ha llamado extimidad, 2001). Si la intimidad se busca porque convalida nuestro estado mental y confirma la creencia de que uno existe al dar validez a nuestras percepciones y pensamientos en la medida en que para otro aquello que

parte, conscientes. Precisamente el propósito del psicoanálisis era robustecer al yo, incrementar el saber sobre uno mismo, adquirir autoconciencia: "donde era Ello ha de ser Yo".

${ }^{5}$ Usamos este término en la línea del neurobiólogo holandés Dick Swaab: "La mente es el resultado del funcionamiento de nuestros cien mil millones de neuronas, y el alma, un malentendido. El uso universal del concepto de alma parece estar basado solamente en el temor que el ser humano tiene a la muerte, el deseo de volver a ver a los seres queridos y la errónea y arrogante idea de que somos tan importantes que algo de nosotros debe quedar a nuestra muerte", El País (28/06/2014). No cabe ya el dualismo mente/cerebro. Somos nuestro cerebro. 
somos, sentimos o pensamos, sí existe (Bleichmar, 1999: 12-13), el niño y la niña necesitan de manera imperiosa cultivar ese sentimiento mediante el apego con las figuras de su entorno afectivo (familia, amigos) de cuya actitud depende la seguridad y la confianza en sí mismos. Por ello, estas figuras, especialmente el padre y la madre, detentan un notable protagonismo en el proceso de mentalización y socialización del niño a través de los sentimientos prosociales de la vergüenza y la culpa, cuya reverberación en la edad madura está en el origen de un buen número de escrituras de infancia contemporáneas.

Así pues, recordar la infancia estimula una búsqueda de las raíces de la subjetividad, el retorno a un mundo físico, afectivo y cognitivo en el que aprendimos a nombrar(nos) y a decir yo para conjurar la imagen fragmentaria en el espejo. Pero es sobre todo un ejercicio de autoconstitución ficcional impulsado por circunstancias y motivaciones del presente del autobiógrafo: si como éramos depende de cómo somos (Schacter, 2007: 168), la infancia es un producto de la memoria del adulto que reconstruye imaginariamente al niño que fue, es decir, al niño que ahora imagina que fue. En este sentido, la infancia es una conjetura o una invención que vamos modificando a lo largo de la vida. El niño que fue, ya no es, pero habita como un fantasma la memoria del adulto y su única posibilidad de restauración es el lenguaje y, de modo particular, la escritura:

Quizá algo de mi modo de ser y de sentir se forjó en el molde definitivo de aquellos días que iban del verano al otoño, y quizá ahora, cuando en septiembre se levanta una súbita brisa precursora de los fríos invernales, algo en mi cuerpo actualiza, pone al día, lejanas vivencias del ayer. Me pregunto (sin ánimo desde luego de obtener respuesta) si los sentidos, desazonados por un escalofrio a deshora, no alertarán a la conciencia de la llegada recurrente de aquella primera tristeza infantil. ¿Somos así de casuales, así de frágiles, de simples? ¿Somos, entre otras cosas, el niño cuya ánima en pena andará siempre errante por las otras edades de la vida? (Landero, 2014: 225-226).

Este fragmento de la autobiografía de Luis Landero, — sobre la que volveremos después-, ilustra cómo el narrador atribuye (con la prudencia del "quizá") el origen de ciertos rasgos constantes de su identidad (cómo es, 
cómo siente) a unas vivencias infantiles que se actualizan, en un mecanismo de memoria involuntaria o inconsciente, por una percepción sensorial: la súbita brisa que en este septiembre presagia el invierno le devuelve la tristeza de los días finales del verano que anunciaban su abandono del pueblo para irse a estudiar al colegio de la capital. La interrogación retórica final retiene la idea de la permanencia del niño interior ${ }^{6}$ cuya ánima en pena anda errante por las otras edades de la vida. El niño ya no es un recuerdo, no pertenece al pasado, sino que queda incorporado al vivir del adulto como una presencia fantasmal y melancólica.

\section{DESDOBLAMIENTOS}

El relato de infancia, como todo discurso autobiográfico, implica un desdoblamiento espacial y temporal entre el yo que escribe aquí y ahora y el yo-personaje de la historia, en este caso la figuración textual del niño o del joven. El primer desdoblamiento equivale, como señala Fernández Romero (2007), a la distancia especular que hace posible tanto la reflexión y el enjuiciamiento del yo o de los yoes del pasado, cuanto el análisis y el comentario (metaautobiográfico) sobre la capacidad de la escritura y de la memoria para dar cuenta de ese desdoblamiento. La mirada del narrador adulto sobre su pasado infantil o juvenil puede colorearse de muy diversos tonos afectivos, morales, estéticos e ideológicos: de la nostalgia a la ironía, de la identificación al rechazo o la extrañeza, de la ternura a la rabia.

El desdoblamiento temporal plantea el problema de la recuperación de la memoria de los yoes que fuimos en el pasado. Ahora bien, el pasado infantil emerge sobre una amplia extensión de olvido; especialmente los primeros recuerdos (hasta los $3 / 4$ años) poseen un carácter fragmentario, aleatorio, en escenas que irrumpen activadas por el ejercicio de rememoración que impulsa la escritura y que, por la acción de la sinécdoque y la metonimia, asumen una potente carga simbólica. Los

\footnotetext{
${ }^{6}$ En esta línea, aunque desde bases psicoantropológicas, se sitúa el arquetipo del niño interior que planteó Carl C. Jung (1959): "el motivo del niño no sólo representa algo que existió en un pasado remoto, sino también algo que existe ahora; es decir, no se trata simplemente de un vestigio sino de un sistema que funciona en el presente cuyo propósito es el de compensar o corregir, de manera significativa, la inevitable excentricidad de la mente consciente" (1994: 52). El niño interior no es una réplica del niño empírico sino un símbolo, un símbolo de plenitud: "En el proceso de individuación, la figura del niño anticipa la síntesis entre los elementos conscientes e inconscientes de la personalidad" (1994: 55).
} 
vacíos de la memoria, las dudas acerca de la fiabilidad de esos episodios aislados, triviales o anecdóticos les dotan, paradójicamente, de una mayor credibilidad: "C'est le tremblé de la mémoire que, d'une certaine manière, l'authentifie" (Lejeune, 1998a: 36).

En todo caso, recuperar un recuerdo es siempre un proceso creativo. Lo que se almacena en el cerebro es sólo el núcleo del recuerdo; cada vez que lo evocamos - salvo en el caso de los recuerdos traumáticos-, ese núcleo se reelabora y reconstruye con detalles que faltan, agregados, creencias y conocimientos adquiridos posteriormente y aportaciones ajenas (Kandel, 2007: 326-327). El pasado tiene mucho de elaboración colectiva. Y ello es evidente en la manera en que la amnesia infantil es paliada por la memoria de otros ${ }^{7}$. Heredamos recuerdos: un patrimonio de historias circula entre los miembros de una familia, de un grupo social, que nos hablan de cómo éramos, qué hacíamos, qué decíamos. La novela familiar. Heredamos silencios y secretos, incluso amores y odios. Toda una red de relatos orales con los que nos rellenan y rellenamos los huecos de una memoria defectiva hasta el punto de que a veces apenas sea posible discriminar si una escena la vivimos realmente o es un recuerdo ajeno incorporado como propio:

yo no tengo recuerdos de antes de los cuatro años de edad que no me hayan venido impuestos, o incluso instalados, ya sea por las palabras de mi madre o bien por alguna fotografía que mi madre ha interpretado para mí, "¿No te acuerdas? Eso fue el día en que cumpliste tres años. Esto fue cuando vivíamos en aquella casa vieja y fea de Warrenton, donde hacia tanto calor y se oía a los mosquitos toda la noche (Coetzee, 2015: 28).

La distancia espacial y temporal que separa al yo de ahora del niño o del joven vuelve no pertinente la cuestión de la exactitud de lo evocado, pero no anula la promesa de veracidad del autobiógrafo: no se trata de

${ }^{7} \mathrm{La}$ infancia, decía Terenci Moix, es siempre "una voz prestada por otros que me reflejaron y acaso desfiguraron" (1993: 65). También el teórico de la autobiografía Philippe Lejeune confiesa que su memoria de infancia es un agujero negro: "Ma mémoire d'enfance est un trou noir. Quand je me penche à la margelle de ce puits, je ne distingue que des figures de cauchemar. J'ai peu de souvenirs, presque tous pénibles. Mes photos d'enfance sont la mémoire de mes parents. J'en suis exclu" (1998b: 213). 
imaginar libremente una infancia, sino de adentrarse en un territorio en que memoria y olvido se entretejen sin solución de continuidad ${ }^{8}$, de indagar en el efecto emocional que en el presente puede producir el recuerdo infantil y en la dificultad de contarlo.

Bajo este marco conceptual comentaré en lo que sigue dos relatos de infancia de escritores nacidos en la década de los cuarenta: La vergüenza (1997) ${ }^{9}$, de Annie Ernaux y El balcón en invierno (2014), de Luis Landero. Cada uno, desde circunstancias personales y culturales particulares, ensaya dar voz a una intimidad marcada por los sentimientos de vergüenza y de culpa generados desde la niñez en la compleja relación con las figuras familiares y con el entorno físico, geográfico y socioeconómico en el que nacieron y crecieron (años 50). Téngase en cuenta además que en este tipo de relatos apenas es posible datar cronológicamente los hechos. La infancia es interiorizada como un tiempo sin tiempo, inmersa en el transcurso lento de las horas, de los días largos, de los juegos y las esperas. Por ello, su evocación se apoya más en lo espacial que en lo temporal: los lugares de la casa y de la escuela, las calles y plazas del barrio y de la ciudad, la naturaleza y los paisajes, todo ello unido a sensaciones olfativas, visuales y táctiles. Por otra parte, aunque los autobiógrafos recurran a objetos, documentos y fotografías que sirven como tiradores de la memoria y que funcionan como realemas o índices de referencialidad mimética, la recreación del pasado está al servicio del presente, de la relación que los autobiógrafos tengan con la historia de su vida, de lo que quieran o puedan hacer con sus recuerdos del pasado lejano - la memoria es un mecanismo adaptativo, y de los lazos emocionales y morales que les vinculan todavía con las imágenes de quienes fueron.

\section{LA VERGÜENZA COMO FORMA DE VIDA}

En ocasiones, la infancia queda afectada por la vivencia de un

\footnotetext{
${ }^{8 " N o}$ sé si la voluntad de escribir sobre mi infancia — de escribir mi infancia — tiene alguna causa. El olvido progresa en mí y se hace parte de un silencio intelectual que, fugazmente, me proporciona algo parecido a un bienestar. Un bienestar vacío. En el olvido están los recuerdos. Advierto que mi aprendizaje de vejez no es otra cosa que la forma que adoptan ahora en mí el pasado y sus sombras" (Gamoneda, 2016: 18).

${ }^{9}$ En la lectura he manejado el original francés de 1997, aunque para las citas y referencias de la novela me he servido de la traducción española de 1999.
} 
acontecimiento violento y doloroso que el niño no puede elaborar y que permanece encapsulado en su memoria, regresando una y otra vez y perturbando el proceso de maduración posterior y la percepción de la identidad, quién se es y quien se desearía ser. Sobre una experiencia de este tipo se articula la autobiografía de Annie Ernaux, significativamente titulada La vergüenza (1997), que comienza de modo abrupto con la descripción de la escena traumática sucedida la tarde del domingo 15 de junio de 1952 en que ella, con doce años, presenció cómo su padre intentó matar a su madre.

El discurso se centra en ese año de 1952, primera fecha concreta de su infancia cuyo tiempo anterior se había deslizado sin calendario, y avanza como un asedio a lo incomprensible, a lo agobiante, a lo indecible de aquella imagen muda y acotada. El punto de partida para dar realidad a la niña que fue son dos fotografías de ese mismo año, una del 5 de junio, vestida de primera comunión, y la otra de agosto con su padre en Biarritz en el curso de una excursión. Parecen la misma, pero entre ellas ha sucedido la destrucción de la infancia: la seguridad de la primera se convierte en el miedo de la segunda, la certeza en desconcierto, el apego en rechazo. En ninguna de las dos se reconoce la narradora; la disociación se explicita en el comentario metatextual entre paréntesis: "Certeza de que 'soy yo', junto a la imposibilidad de reconocerme, "no soy yo"” (Ernaux, 1999: 22).

El libro es un intento de entrar en el cuerpo y en la mente de la niña que había antes de aquella tarde de domingo para entender el porqué del sentimiento de vergüenza que desde entonces la invadió y que la hizo mantener en secreto lo ocurrido hasta el momento en que, cuarenta y tres años después, decide escribirlo para desentumecerlo y disolverlo "en las generalidades de las leyes y el lenguaje" (Ernaux, 1999: 35):

Lo que quiero es encontrar las palabras con las que me pensaba a mi y al mundo que me rodeaba, decir qué era lo normal y lo inadmisible para mí, e incluso lo impensable. Pero la mujer que soy en 1995 es incapaz de penetrar en aquella niña del año 1952 que lo único que conocía era su pequeña ciudad, su familia y su colegio, y que sólo tenía a su disposición un léxico muy reducido. Y, ante ella, la inmensidad del tiempo por vivir. No existe una auténtica memoria de uno mismo (Ernaux, 1999: 34). 
No se pretende evocar la infancia, sino investigar y reconstruir del modo más distanciado y frío posible las leyes, los ritos, las creencias, los valores y los lenguajes a través de los que aquella niña se percibía a sí misma y a los demás. La estrategia para esa reconstrucción no es narrativa sino etnológica (1999: 35). Ernaux revisa archivos y hemerotecas, traza la topografía de su pequeña ciudad de la Francia profunda (entre Le Havre y Rouen) de principios de los $50^{10}$, que es a la vez una "autosocio-biografía" 11 de un espacio provinciano, cerrado y murmurador, donde cualquier conducta debía sujetarse a códigos predeterminados sobre lo correcto y lo incorrecto, lo que está bien (visto) y lo que está mal (visto). A través de una prosa lacónica y austera, casi en grado cero (frases nominales, enumeraciones, desnudez figurativa, predominio del presente enunciativo), y de los comentarios metaautobiográficos, se impone la voz y la perspectiva ideológica de la adulta, que es consciente de estar despojando aquellas calles de su infancia del encanto que debieron tener, pero la verdad que le trae su memoria está teñida de la aspereza del resentimiento, latente ya en 1952 al apreciar el contraste entre su barrio sombrío de clase baja y la zona de casas elegantes cuyas fachadas bastaban para saber que sus moradores "no eran como nosotros" (Ernaux, 1999: 45). La niña había aprendido a moverse en dos esferas social y económicamente alejadas, la de su familia de pequeños propietarios de origen obrero y la de la escuela femenina privada y católica de la ciudad, a la que la envían los padres como la vía de desclasamiento y ascenso social: "Es necesario que des una buena imagen en el colegio". Aquí su vida cotidiana estaba controlada al milímetro por un conjunto de reglas que la narradora enumera; son las tablas de la ley de su (de)formación sentimental y quizá por ello, a medida

\footnotetext{
${ }^{10}$ Esa ciudad de la Normandía (Yvetôt) se nombra solo con la inicial Y, porque en el libro ya no es un lugar geográfico sino "el lugar de origen sin nombre en el que, cuando vuelvo, me siento presa de un torpor que me impide pensar y hace desaparecer de mi mente casi todos los recuerdos concretos, como si fuera a tragarme de nuevo" (Ernaux, 1999: 40). En aquel momento, además, aún no era Annie Ernaux sino Annie Duchesne.

11'JJe me considère très peu comme un être unique, au sens d'absolument singulier, mais comme une somme d'expériences, de déterminations aussi, sociales, historiques, sexuelles, de langages, et continuellement en dialogue avec le monde (passé et présent), le tout formant, oui, forcément, une subjectivité unique. Mais je me sers de ma subjectivité pour retrouver, dévoiler des mécanismes ou des phénomènes plus généraux, collectifs" (Ernaux, 2003: 44-45).
} 
que las dice, parece decrecer la extrañeza inicial que sintió ante la foto de la comulgante:

El "texto" aclara la foto, que, a su vez, ilustra el texto. Distingo en la foto a la pequeña y aplicada alumna del pensionado, dotada de poder y de certezas en un universo que para ella es la verdad, el progreso y la perfección, y donde nunca se imagina poder desmerecer (Ernaux, 1999: 85-86).

Esa seguridad es precisamente la que se derrumba después del asalto: el trauma no procede solo de la escena de violencia doméstica sino de la imposibilidad de encajarla y entenderla dentro de la estructura emocional y los esquemas socio-ideológicos asumidos por la niña. Sus dos mundos antes compatibles, se separan radicalmente: "habíamos dejado de pertenecer a la categoría de la gente correcta... Me había convertido en una persona indigna del colegio privado... Había entrado en el ámbito de la vergüenza" (Ernaux, 1999: 104). Su conducta posterior quedará marcada por el rechazo a su medio familiar y social. y por la conciencia vergonzante de su pertenencia a la clase baja, con sus síntomas de aislamiento e inhibición, fingimiento de una identidad en función de los otros, estado de alerta por miedo a que sus modales, su acento, sus gestos la delaten:

Era normal tener vergüenza, como si ésta fuera una consecuencia inevitable del oficio de mis padres, de sus problemas de dinero, de su pasado de obreros, de nuestra forma de ser. De la escena de aquel domingo de junio. Para mí, la vergüenza se convirtió en una forma de vida (Ernaux, 1999: 125).

No parece, llegados al último párrafo, que la escritura haya logrado cauterizar el drama íntimo ni restaurar la fragmentación del yo. Hay pasados que son irredimibles:

Miro la foto de Biarritz. Mi padre murió hace veintinueve años. Ya no tengo nada en común con la niña de la foto salvo la escena del domingo de junio que lleva en la cabeza y que me ha hecho escribir este libro, porque esa escena nunca me ha abandonado. Es lo único que hace que esa niña y yo seamos la misma... (Ernaux, 1999: 126- 
127).

El comentario metaautobiográfico constata la persistencia del recuerdo y de sus efectos de vergüenza y humillación ${ }^{12}$; la intimidad convulsa del yo de la adulta ha encontrado en la mirada etnológica una vía para manifestarse, pero apenas desvela el rostro borroso de la foto de aquella niña de doce años que se había quedado de pronto excluida de la verdad, el bien y la luz, virtudes patrimoniales de la clase dominante. Sin embargo, el hecho mismo de hacer pública su experiencia posee una dimensión performativa $^{13}$. Romper el silencio de la vergüenza puede posibilitar la reconfiguración de la memoria de infancia y de su relato, encallado en la repetición incesante e interminable de las imágenes indecibles.

\section{ENTRE LA DEUDA Y LA CULPA}

En 2014 el novelista Luis Landero publica un texto autobiográfico, El balcón en invierno ${ }^{14}$, que surge — según nos cuenta - de una crisis como autor de ficciones, de un estado de insatisfacción y tristeza que le conduce a ensayar la posibilidad de escribir sobre su propia vida. El texto se desenvuelve en un doble nivel: el plano metanarrativo, constituido por el propio proceso de redacción del libro, iniciado en septiembre de 2013 y terminado en marzo del año siguiente, en el que se repasa el modo azaroso en que se fragua su vocación literaria y se reflexiona sobre lo que los libros y la lectura han significado para él; y el plano de la historia, que se remonta a otro septiembre de unos cincuenta años atrás, poco después de la muerte

\footnotetext{
${ }^{12}$ Advierte Barbara Havercroft que el discurso metatextual "inscrit et engendre une méta-honte, une honte au second degré. Non seulement Ernaux a honte d'avoir eu honte de ses parents et de son milieu ouvrier, mais elle a également honte du libre même de la honte qu'elle este en train d'écrire" (2005: 22).

13“'La honte est motrice dans le désir d'écrire mais elle ne correspond pas à la honte telle qu'elle vous emplit, telle qu'elle agit et qu'elle reste, malgré tout, après l'écriture. Elle reste ineffaçable mais d'avoir été écrite, elle est comme dissoute, partagée avec les autres, en quelque sorte. J'écris la honte avec l'idée qu'elle trouvera ne fût-ce qu'une personne pour la comprendre. C'est ce sentiment-là qui m'anime." (Ernaux, 2016).

${ }^{14}$ Diversos contenidos de este libro se encuentran prefigurados en las páginas de un texto anterior de Landero titulado Entre líneas: el cuento o la vida (2001). Se trata de un conjunto de cuentos protagonizados por un personaje de ficción, Manuel Pérez Aguado, que se alternan con reflexiones y evocaciones de la infancia en primera persona de evidente base autobiográfica.
} 
del padre del narrador, que era un adolescente de 16 años y que entonces vivió aquella muerte como una liberación, lo que más tarde se convertirá en un profundo sentimiento de culpa. El sujeto, el yo autobiográfico que aquí se va dibujando "no es una sustancia sino un huésped de espectros" (Loureiro, 2001: 24). De hecho, la presencia espectral del padre le abrumará siempre al estar arraigada en la deuda y la culpa:

Yo personificaba para él el gran fracaso de su vida, y él era para mí la viva personificación del miedo. Aun hoy, su presencia evocada sigue siendo tan imponente y problemática como cuando vivía. Poco después murió, y aquel es el episodio central de mi vida y el manantial de donde brota ciego e incontenible mi destino. Todo lo que ocurrió después ha estado presidido por los acontecimientos de esa tarde de mayo. Y han pasado los años y yo creo que no ha habido un solo día de mi vida en que no haya rememorado las circunstancias de su muerte. Le doy vueltas y vueltas sin lograr otra cosa que toparme una y otra vez contra lo irreparable (Landero, 2014: 88-89).

El episodio central no es propiamente la muerte del padre, sino el haberlo abandonado en la habitación del hospital a sabiendas de que se moría - "Lo sabía con tanta certeza como si ya hubiese ocurrido. Una certeza alimentada quizá por una oscura, recóndita, innombrable esperanza" (2014: 90)_, el haber huido a la calle con sus amigos ignorando su mirada indefensa que le demandaba afecto y protección. El recuerdo de ese último y definitivo des-encuentro desencadena una culpa que se enquista en su interior, que intentará conjurar sin éxito a lo largo de su vida y que es lo que provoca finalmente la escritura de este libro: saldar la deuda, reconciliarse con (el espectro de) el padre, o sea, consigo mismo:

Y me fui. Lo que no sospechaba, claro está, es que el camino que iniciaba en ese instante fuese tan largo y tan definitivo, porque ya no me dirigía a la calle sino hacia el futuro, era alli donde comenzaba mi verdadero futuro, el que con el correr de los años me traería hasta esta mañana en que escribo estas líneas, deudoras, como casi todo lo que he escrito en mi vida, de aquella tarde incesante de mayo. Y es que a veces el pasado no acaba nunca de pasar (Landero, 2014: 
$90)$.

Y para explicar(se) esa huida, la evocación retrocede mediante otra analepsis hasta su infancia en un pueblo de Extremadura hacia los años 50. En contraste con el adolescente crispado y arisco, el niño vive libre y alegre en contacto con el campo y la naturaleza, en el entorno cordial de una familia de labradores, hombres curtidos y mujeres sabias en el arte de contar - como su abuela Frasca—, que le transmiten noticias, leyendas e historias mágicas en las tertulias y coloquios compartidos alrededor del fuego. El narrador se abandona a la idealización nostálgica de aquel mundo infantil "de fantasía y palabras malabares" y de aquella gente campesina que suplía la falta de estudios con "los refinamientos propios de una cultura milenaria" (2014: 178).

Pero su padre quería algo mejor para su hijo y con gran esfuerzo económico lo envió interno con ocho años a un colegio de curas en Madrid, lo que supuso un descalabro psicológico definitivo para el niño. En el colegio se avergüenza de sus modales y su acento, pierde la seguridad y la autoestima, se queda huérfano de mundo y de realidad. Y ocurre entonces la primera crisis moral que el yo infantil afronta - decidir entre hacer lo debido o lo indebido según las expectativas paternas-, y que el yo adulto considera determinante en la constitución de su identidad: el niño encuentra en la fantasía y la mentira los medios para escapar de la autoridad del padre: “... la imaginación, con sus mentiras tan necesarias y sinceras, venía a anudar los hilos sueltos de una realidad fragmentaria y caótica" (2014: 77). Este será paradójicamente el aprendizaje para su futura profesión como novelista y el principio de un trayecto de fracaso escolar y luego laboral, y de un conflicto cada vez más enconado con el padre que, en su desesperación, lo humilla al obligarlo a llevar puesto por la calle un mono azul de mecánico y unas alpargatas de lona, experiencia que el narrador califica como uno de los momentos esenciales de su vida inmunes al olvido: "Yo creo que nunca he sentido tanta vergüenza, tanta humillación, tanto odio contra mi padre y contra el mundo como en esos momentos" (2014: 64). Las mentiras siguen y el desencuentro se cronifica y se vuelve más violento y amargo. En este contexto de tremenda ambivalencia hacia el padre (amor y odio, respeto y desprecio, agradecimiento y rencor) sucede su fallecimiento en las circunstancias ya descritas. 
Es precisamente esta ambivalencia la que se procura (inútilmente) resolver en la escritura: el narrador indaga sobre el pasado de su padre durante la guerra, intenta comprender las razones de su frustración y de su amargura, incluso quiere imaginarlo, a raíz de un comentario de su madre, como un "oficiante" de un rito sagrado leyendo en voz alta a los segadores, a la luz del candil, un capítulo del único libro que había en la casa, El calvario de una obrera o los mártires del amor de León Montenegro (2014: 72). Páginas alentadas por el deseo de saber quién fue su padre antes de serlo, ese hombre que él no había conocido y que quizá pudiera admirar. Pero, a pesar de ese esfuerzo, la figura interiorizada del padre sigue siendo oscura, connotada de las emociones de miedo y culpa. Demasiada deuda que pagar, "demasiado padre para mí". La necesidad de reconciliarse y la imposibilidad de la reconciliación han mantenido viva la presencia fantasmal del padre en la memoria del hijo y en las ficciones del escritor: "En parte mis temas como novelista han sido impuestos por aquella experiencia con mi padre. Se ha convertido en mi musa, que era lo último que hubiera deseado" (Landero, 2013) ${ }^{15}$.

Los rasgos que el sujeto autobiográfico se atribuye - "la ambigüedad, el desarraigo, el merodeo, la vaguedad de contornos, la indefinición de las tareas"(Landero, 2014:97) — se perfilan como resultado de aquel obligado desapego infantil: un tipo a la intemperie en busca de un lugar y de un refugio, cuya aventura hasta convertirse en escritor se relata en los capítulos metanarrativos. La literatura será su lugar, los libros su refugio: "Esconderte en un libro, en el cálido cubil de las palabras, eso es lo que has hecho tantas veces, como de niño en los desvanes" (Landero, 2014: 223).

Una visión intensamente melancólica, por momentos elegíaca, atraviesa, en fin, la rememoración de aquel niño de campo y de aquel mundo labriego desaparecido. Todo parece haber ocurrido hace mucho tiempo, incluso fuera del tiempo. Nada de aquello sobrevive fuera de la memoria del narrador. Esta deriva melancólica enlaza con otra deuda de carácter ético, que no genera culpa sino reconocimiento: la contraída con sus parientes y con aquellas gentes humildes y anónimas - labradores, hojalateros, artesanos, carpinteros...- con sus costumbres y sus comidas,

${ }^{15}$ Sobre la presencia del padre en la obra de Landero pueden verse Gómez-Vidal (2013), Antonio Rivas (2017) y Ruiz de Aguirre (2015). 
con su prosodia brusca y su léxico rústico ya perdido, con las vidas de la generación que sufrió la guerra y la posguerra y que sacrificaron todo para darle un futuro mejor a sus hijos. La intimidad del sujeto autobiográfico se percibe, a la manera de Levinas, conformado por las huellas de otros que le han precedido, poblada por esos fantasmas del pasado que le han hecho ser el que es. Y, en este sentido, es iluminadora la reflexión de A. Loureiro:

el sujeto es a la vez exceso y defecto. Es exceso en cuanto que todos los fantasmas que ha interiorizado, y sin los que no podría tener conciencia de sí, se añaden a lo que el sujeto aspira a considerar como yo propio, como propiedad personal, como singularidad. $Y$ es defecto en cuanto que, constituido por las marcas de los otros, la autoconciencia solo puede ser una no-coincidencia, un autoextrañamiento, una falta ... y sobre todo, una deuda (o su reverso, la culpa), pues el sujeto sólo se puede autopercibir por medio de ese diálogo con sus huéspedes fantasmáticos. Y el diálogo más terrible, consecuente e inevitable se da con los muertos... (2001: 27-28).

La experiencia singular del autobiógrafo se integra en la memoria colectiva de aquella España rural hoy envejecida y despoblada ${ }^{16}$. Al final, el libro se convierte en un acto de homenaje y en un testimonio contra el olvido: "Pienso que acaso estas páginas puedan servir para que lo vivido no se pierda del todo, y para que algún día los futuros descendientes de los hojalateros ambulantes puedan captar un destello, un eco de las vidas anónimas de sus antecesores..." (Landero, 2014: 244).

\section{CONCLUSIÓN}

La representación de la infancia que ofrecen estos dos autores plantea interesantes elementos de convergencia y divergencia autoriales y textuales. Nacidos entre 1940 (Ernaux) y 1948 (Landero) en el entorno de

\footnotetext{
${ }^{16} \mathrm{El}$ fenómeno de la despoblación del mundo rural, iniciado con la emigración de los años sesenta, se ha ido agudizando en las décadas siguientes ante la indiferencia y el desinterés de los gobiernos y las instituciones. Esta realidad ha sido objeto de tratamiento literario en obras recientes de autores como Julio Llamazares, Jesús Carrasco, Alejandro López Andrada y, de manera particular, se ha visibilizado en el libro de viajes de Sergio del Molino titulado La España vacía. Viaje por un país que nunca fue (2016). No es ajeno a esta mirada solidaria el libro de Landero.
} 
una ciudad de provincias de Normandía y de un pueblo de Extremadura, proceden de familias de clase obrera y campesina que realizan un notable esfuerzo económico para darles a su hija (única) y a su hijo (único varón) una formación educativa esmerada que les permita ascender en un sistema social que entonces empezaba a dar señales de cierta movilidad. Y ambos lo consiguen y llegan a ser autores de prestigio en el panorama literario francés y español.

Pero ese proceso alteró profundamente, por razones distintas, sus vínculos afectivos con las figuras familiares y con el entorno social, y los dejó desasistidos y descolocados, sin lugar (físico y/o social) en el mundo, hasta el punto de determinar no sólo su conformación sentimental, ideológica y moral posterior, sino también su imaginación y su temática literarias. Y es que lo que cada uno hace con la memoria de la infancia y el modo en que lo hace está en función, como dijimos al principio, de la relación emocional, ética e ideológica que el/la autobiógrafo/a actual establezca con su pasado infantil.

La narradora adulta de Ernaux no se reconoce en la niña que fue salvo en la continuidad del resentimiento y del malestar que se adueñaron de ella desde que la escena de la violencia la hizo consciente de su inferioridad social; la escritura surge como una necesidad de dar voz al silencio de aquel sentimiento de vergüenza aún vigente. Controlada la emoción, en un tono ensayístico y descriptivo, la autobiógrafa convierte a la niña (y a sí misma) en objeto de estudio sociológico ${ }^{17}$.

En la autobiografía de Luis Landero, el narrador reviste de emoción y nostalgia el tiempo de infancia y el escenario rural en que creció porque es ahí donde sitúa su particular paraíso perdido, del que su padre lo apartó para hacer de él "un hombre de provecho". A diferencia de la niña Annie, que se integra en el colegio religioso y se ajusta su ideario social, religioso y estético, el niño Landero rechaza el colegio y se resiste a cumplir las expectativas paternas de donde surge el conflicto emocional y moral que marca su adolescencia a la deriva. La escritura surge como una necesidad de restaurar la figura del padre en su memoria y liberarse de una culpa.

En los dos, la memoria personal de la infancia aparece traspasada por la presencia fantasmal de los otros, pero los efectos divergen por el

${ }^{17}$ Un estudio que no es ajeno a la influencia que ejercieron sobre ella las lecturas de Pierre Bourdieu. Véase Romeral Rosel (2018). 
modo en que han sido interiorizados. En Landero, los otros son los suyos, en los que no ha dejado de reconocerse nunca: el grupo familiar femenino que lo acoge y las gentes del mundo rural cuya memoria colectiva constituye el componente más amable e idealizado de su pasado infantil. La melancolía acaba impregnando escenas y palabras que transmiten el afán de apropiarse de algo perdido y que, en realidad, nunca se ha tenido.

En Ernaux, esos otros se materializan en dos bloques radicalmente diferenciados en su nivel económico y en sus rasgos y actitudes: su mundo familiar de clase obrera, con su acento y sus modales vulgares, y el mundo ajeno, el de la clase superior, donde residen la urbanidad, el refinamiento y la distinción. Bastantes años después, la autora confiesa en una interesante entrevista la relación de su escritura con el deseo de denunciar las formas de dominación cultural que generan las vivencias de vergüenza e indignidad que la alejaron de sus padres en la adolescencia:

M.C-M.: Ecrire sur la classe ouvrière est-il un moyen de préserver un lien avec ceux que vous avez quittés, de compenser le sentiment de trahison? Peut-on interpréter vos livres comme une contribution à la mémoire collective de "la classe la plus nombreuse et la plus pauvre" (Saint-Simon)?

A. E.: Il y a tout cela dans mon écriture, je crois. Rétablir un lien que je me suis mise à refuser à l'adolescence, détestant par exemple que ma mère revendique, auprès de la directrice du pensionnat, avoir été ouvrière durant toute sa jeunesse, "Vous savez, ma Sœur, je n'en rougis pas!'. Et moi, intérieurement, je me disais: "Mais elle n'a pas besoin de dire ça!", comme si elle avouait, malgré elle, une infériorité. Ecrire, c'est justement me donner le droit, non seulement de dire ça, mais aussi de dénoncer les hiérarchies, la domination culturelle qui font que, implicitement, une ouvrière est au bas de l'échelle sociale. C'est vouloir retourner l'indignité sociale en dignité, rendre justice aux dominés. (Ernaux, 2016).

La escritura de la infancia, en fin, da consistencia figurativa a la intimidad del autobiógrafo adulto: ese ámbito de pensamientos, deseos y recuerdos habitado por las imágenes borrosas de sí mismo — los yoes que 
imagina que fue - y atravesado por las huellas persistentes de los otros en sus varias modulaciones sociales, éticas y sentimentales.

\section{REFERENCIAS BIBLIOGRÁFICAS}

ABRAMS, J. (ed.) (1994). Recuperar el niño interior, Carlos Figueras (trad.). Barcelona: Kairós.

BAENA, R. (2000). "Childhoods: la autobiografía de infancia como subgénero narrativo en auge". RILCE 16.3, 479-89.

BLEICHMAR, H. (1999). "Del apego al deseo de intimidad: las angustias del desencuentro". Aperturas psicoanalíticas: Revista de psicoanálisis 2, 1-18 (también en https://aperturas.org/articulo. php? articulo $=0000074 \& a=$ Del-apego-al-deseo-de-intimidad-lasangustias-del-desencuentro [07/01/2019]).

BRAUNSTEIN, N. A. (2008). Memoria y espanto. O el recuerdo de la infancia. México: Siglo XXI.

CABO, F. (2001). Infancia y modernidad literaria. Madrid: Biblioteca Nueva.

COETZEE, J. M. (2000). Infancia, Juan Bonilla (trad.). Barcelona: Mondadori.

COETZEE, J. M. y KURTZ, A. (2015). El buen relato. Conversaciones sobre la verdad, la ficción y la terapia psicoanalítica, Javier Calvo (trad.). Barcelona: Random House.

EAGLEMAN, D. (2013). Incógnito. Las vidas secretas del cerebro. Barcelona: Anagrama.

ERNAUX, A. (1997). La honte. París: Gallimard.

(1999). La vergüenza, Mercedes y Berta Corral (trads.). Barcelona: Tusquets. (2003). L'écriture comme un couteau. Entretien avec Frederic-Yves Jeannet. Paris: Stock.

(2016). "Écrire la violence sociale. Entretien avec Annie Ernaux" [entrevista de Manuel Cervera Marzal]. Contretemps. Revue de critique communiste, 1 de agosto, www.contretemps.eu/ecrire-laviolence-sociale-entretien-avec-annie-ernaux [9/03/2019].

FERNÁNDEZ ROMERO, R. (2001). "El recuento de la infancia y la juventud". Cuadernos Hispanoamericanos 617, 7-13. 
(2007). El relato de infancia y juventud en España (1891-1942). Granada: Universidad de Granada.

GAMONEDA, A. (2016). Niñez. Antología, Amelia Gamoneda (ed.). Barcelona: Calambur.

GÓMEZ-VIDAL, E. (2013). “De Juegos de la edad tardía a Hoy, Júpiter. En pos de la figura del padre”. En Luis Landero, I. Andrés Suárez y A. Rivas (eds.), 167-188. Neuchâtel: Universidad de Neuchâtel.

HAVERCROFT, B. (2005). "Dire l'indicible: trauma et honte chez Annie Ernaux". Roman 20-50, 40, 119-132.

JUNG, C. G. (1994). "Psicología del arquetipo infantil". En Recuperar el niño interior, J. Abrams (ed.), 47-57. Barcelona: Kairós.

KANDEL, E. R. (2007). En busca de la memoria. El nacimiento de una nueva ciencia de la mente. Madrid: Katz Editores.

LANDERO, L. (2001). Entre líneas: el cuento o la vida. Barcelona:

Tusquets.

(2013). "Con cada novela hay un tiempo de idilio. Con esta se está prolongando", entrevista de Tereixa Constenla. El País, 26 de enero (también en https://elpais.com/cultura/2013/01/22/ actualidad/1358862459_272789.html [10/01/2019]).

(2014). El balcón en invierno. Barcelona: Tusquets.

LEJEUNE, P. (1998a). Les brouillons de soi. Paris: Seuil. (1998b). "Photos d'enfance". En Pour l'autobiographie. Chroniques, 213-214. Paris: Seuil.

(2003). "Votre enfance en cinq leçons". En Le récit d'enfance et ses modèles, A. Chevalier y C. Dornier (eds.), 281-296. Caen: Presses Universitaires de Caen.

LOUREIRO, A. G. (2001). “Semprún: memorial de ausencias”. Cuadernos Hispanoamericanos 617, 21-29.

(2016). Huellas del otro. Ética de la autobiografía en la modernidad española. Madrid: Postmetrópolis Editorial.

MATEO DÍEZ, L. (1997). Días del desván. León: Edilesa.

MOIX, T. (1993). El peso de la paja, I. Barcelona: Plaza y Janés.

PARDO, J. L. (1996). La intimidad. Valencia: Pre-Textos.

RIVAS, A. (2017). "La autobiografía como relato de reconciliación: $E l$ balcón en invierno". Revista Turia 121-122, 235-242.

ROMERAL ROSEL, F. (2018). "Annie Ernaux: una autobiografía sometida a constante autorrevisión”. Signa 27, 107-126 (también 
en $\quad$ http://revistas.uned.es/index.php/signa/article/view/21851 [05/04/2019]).

RUIZ DE AGUIRRE, A. (2015). "La figura del padre, símbolo esencial en la narrativa de Luis Landero". CÉFIRO: Enlace hispano cultural y literario 14, 1-14.

SCHACTER, D. L. (2011). Los siete pecados de la memoria. Barcelona: Ariel.

SWAAB, D. (2014). Somos nuestro cerebro. Cómo pensamos, sufrimos y amamos. Madrid: Plataforma Editorial.

TISSERON, S. (2001). L'intimité surexposée. París: Hachette Litératures.

Recibido el 5 de abril de 2019.

Aceptado el 3 de junio de 2019. 